\title{
A review of survivability and remedial actions of tidal current turbines
}

\section{Long Chen ${ }^{\mathrm{a}, \mathrm{b}}$, Wei-Haur Lam ${ }^{\mathrm{a}, \mathrm{b}, *}$}

a State Key Laboratory of Hydraulic Engineering Simulation and Safety, Tianjin University, Peoples Republic of Chin

${ }^{\mathrm{b}}$ Marine Renewable Energy Research Group, Department of Civil Engineering, Faculty of Engineering, University of Malaya, Kuala Lumpur 50603, Malaysia

\section{A R T I C L E I N F O}

Article history:

Received 8 October 2013

Received in revised form

25 October 2014

Accepted 14 November 2014

Available online 6 December 2014

Keywords:

Tidal current turbines

Extreme weathe

Fatigue failure

Fatigue faill
Corrosion

Corrosion
Marine fouling
A B S T R A C T

Tidal current energy is one of the most predictable ocean renewable energies. Survivability of the device used to harness tidal power and its remedial actions are critical to ensure a successful power generation. Marine environment is harsh with the continuous attacks of waves, current, saline water and microorganism. Support structures are discussed including gravity base, monopile, tripod/piled jacket and floating structure. Extreme weather increases the wave height and current speed to produce high loading at the turbine. Support structure is designed to sustain the loadings from the extreme weather. Protective seabed unit should be included to prevent the seabed scouring. Corrosion reduces the strengths of rotor, support structure and nacelle. Penetration of sea water into nacelle may damage the generator. Scheduled examination is important to ensure water tight condition of nacelle. Marine fouling from microorganism needs the proper painting as protection. The study presents the survivability of tidal current turbine and suggests the remedial actions to protect the device.

Contents

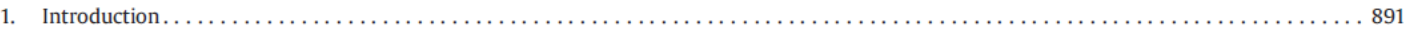

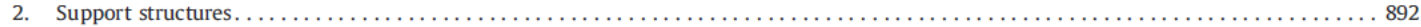

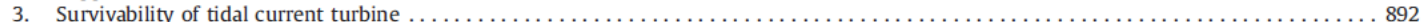

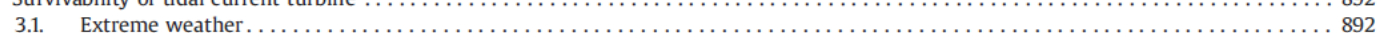

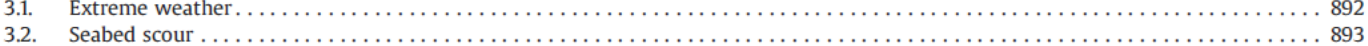

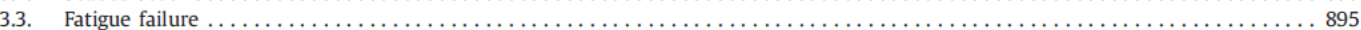

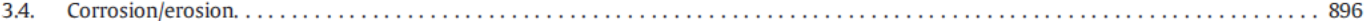

3.5. Marine fouling

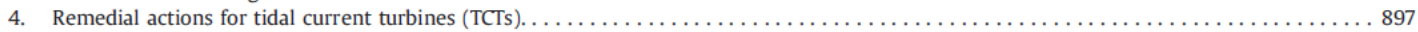

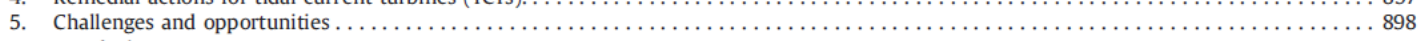

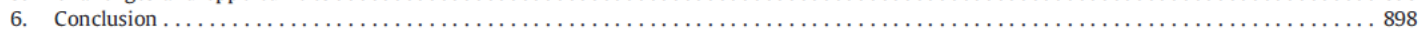

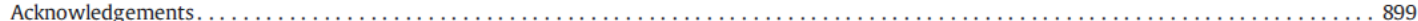

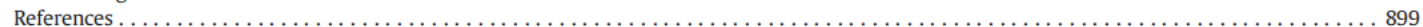

\section{Introduction}

Brundtland Report from United Nation coined the term "sustainable development" in 1987. Sustainable development refers to the development that meets today's generations needs without compromising those future generations [1]. As world population

*Corresponding author. Tel.: +603 79677675; fax: +60 379675318

E-mail address: joshuawhlam@hotmail.com (W.-H. Lam).

http://dx.doi.org/10.1016/j.rser.2014.11.071

1364-0321/@ 2014 Elsevier Ltd. All rights reserved. grows at an average rate of $0.9 \%$ per year to an estimated 8.7 billion population in 2035 , the energy consumption will sharply increase when more peoples move to urban areas [2]. Energy demands depend on the world energy policies, global GDP growth, world population growth, energy pricing, fossil-fuel subsidies $\mathrm{CO}_{2}$ pricing and development of energy technologies as described in World Energy Outlook 2013 [2]. Future energy demands are hard to meet without burning of fossil fuels continuously or depending on nuclear power. Exploration of renewable energy is one of the expected solutions to achieve the sustainable development. 
The oceans have tremendous untapped natural resources, which are able to make significant contribution to our future energy demands. Several types of ocean sources have been defined as potential sources to generate electricity including tidal barrage, tida current energy, wave energy, ocean thermal energy and salinity gradient energy $[3,4]$. Researchers face many barriers on finding highly applicable and cost effective technologies to develop these sources.

Tidal current is one of the most advantageous resources, which can be extracted from the rise and fall of sea levels caused by the gravitational force exerted by the moon and sun and the rotation of the earth. Tidal current energy is more predictable compared to wind and wave energies. Tidal current sources are easier to be quantified and predicted [5,6]. A number of devices have been designed to harness tidal energy with wide range of shapes, sizes and forms [6]. These inventions harness potential kinetic energy of tides and convert the energy to electricity principally. Tidal curren turbine can be categorised as horizontal axis and vertical axis tida turbines [8]. Horizontal axis tidal current turbines (TCTs) are the most common device with the rotation axis in parallel to the direction of current stream [9]. Vertical axis TCTs rotates about a vertical axis in perpendicular to the current stream [10].

Extracting the kinetic energy from ocean is more challenging compared to the wind on land. Wind turbine is vulnerable to the cyclones in the extreme weather [11]. For the marine environment, extreme sea conditions have to be considered for the survivability of TCTs. Sole consideration of the extreme weather in ocean is not able to ensure the survivability of tidal current turbine. The effectiveness of mooring system to hold the tidal current turbine under extreme condition is examined to provide guideline in design. The current work firstly introduced the mooring systems of gravity base, monopile, tripod and floating structure. Tida current turbines are vulnerable to the damage of seabed scour. The potential scour of various foundations are discussed and followed by the discussion on the fatigue failure of blades, corrosion failure of saline water attack and the hydrodynamic failure of befouling at the blades. Installation and operation of TCT are harsh in the marine environment. The current work unveiled the potential damages of the tidal current turbine in ocean and provided protective actions to ensure the survivability of turbine.

\section{Support structures}

The support structure of TCTs is of significant importance in tidal current energy system. Prior assessment of the support structure of TCTs was carried out before approaching the survivability of TCTs. Based on the current status of TCTs, four basic support structures for TCTs are as follows [6]:

(1) Gravity structure: this gravity structure is made up of large steel or concrete base column. It can resist overturning by its self-weight. The steel component of this gravity structure adds some advantages to itself, such as ease of production, transportation, and installation.

(2) Monopile structure: this type of structure is made up of a largediameter hollow-steel beam. The beam is penetrated approximately $20-30 \mathrm{~m}$ into seabed while the seabed conditions are soft. If the rock is harder, pre-drilling, positioning and grouting may be the methods to install this structure.

(3) Tripod/piled jacket structure: each of the corners of the structure's base is anchored to the seabed by using steel piles. The steel piles are driven approximately $10-20 \mathrm{~m}$ into the seabed depending on the seabed conditions. This type of structure is well understood since it has been widely applied in the oil industry. Compared to other structures, this structure has lighter structural loading.

(4) Floating structure: floating structure provides the optimum solution for the placement of devices in deeper water conditions. This type of structure is made of mounting device and floating vessel which is moored to the seabed using chains, wire or synthetic rope. The illustration of all the aforementioned support structures can be found in works [12,13].

Monopile structure has been applied on the Seaflow and Seagen from marine current turbine (MCT). Monopile was used to support the single rotor of Seaflow rated $330 \mathrm{~kW}$ and twin-roto of Seagen rated 1.2 MW. Monopile is able to provide firm support with the lifting ability to rise up the rotor for maintenance. The cost is higher compared to the floating structure. Size and weight of turbine are increasing in parallel to the demand of higher rated power for a single device. Tripod is more suitable to hold the heavier turbine. However, tripod and gravity base structures have larger contact area between the structure and seabed leading to higher chances of seabed scour. Rourke et al. [6] has summarised all the devices in detail including their dimensions, features and status of development. The condition of TCTs under the extreme weather, seabed scour, blade failure, corrosion and biofouling are discussed by relating to the support structures.

\section{Survivability of tidal current turbine}

\subsection{Extreme weather}

The impacts of extreme weather to the TCTs and its support structure are discussed substantially in this section. Sea environment is harsh due to the intrinsic nature of sea state. Extreme events occur frequently such as hurricane, typhoon, tsunami and storm. The extreme events bring along the extreme wave and strong wind which would have severe impacts on the survivability of TCTs.

McCann et al. [14] stated that the extreme conditions considered are based on the combined probabilities of governing environment, such as current speed and wave height. Identification of the maximum loadings of storm can prevent the turbine components from damages. The generic tidal blade model used requires the blade root and tower base to withstand the moment approximately at 5 and $50 \mathrm{MN} \mathrm{m}$, respectively. The simulated environmental condition is a 50-year return storm with $13 \mathrm{~m}$ wave height and $10 \mathrm{~s}$ wave periods. The detail of the simulation is shown in Table 1 [14].

Grogan et al. [15] presented a combined hydrodynamic-structural design methodology for a commercial scale $(1.5 \mathrm{MW})$ tidal turbine. The loading analysis of the turbine blades has been conducted. Grogan et al. [15] found that the high bending moments of the turbine blades during operation life may prohibit the up-scaling of

Table

Extreme 50-year storm design load case conditions.

\begin{tabular}{ll}
\hline Design load case & 50-Year return storm \\
\hline Wind speed & $25 \mathrm{~m} / \mathrm{s}$ at $10 \mathrm{~m}$ height \\
Wind-induced surface current & $0.625 \mathrm{~m} / \mathrm{s}$ \\
Extreme 50 year regular wave & \\
$H_{s}$ (wave height) & $13 \mathrm{~m}$ \\
$T_{p}$ (wave period) & $10 \mathrm{~s}$ \\
Normal current speed at hub height & $2.2 \mathrm{~m} / \mathrm{s}$ \\
Current direction & Co-direction with wind and waves \\
Water level & $40 \mathrm{~m}\left(\mathrm{MWL}^{\mathrm{a}}\right)+2 \mathrm{~m}$ (storm surge) \\
\hline
\end{tabular}

${ }^{a}$ MWL: mean water level. 
the blades. The structural performance of glass fibre reinforced polymer (GFRP) and carbon fibre reinforced polymer (CFRP) as spar cap materials has been compared. Grogan et al. [15] claimed that GFRP is not a suitable material used to construct the main structural components of a large tidal turbine blade. The selection of materials is of significant importance for the TCTs to sustain storm during the service life.

The reliability of rotor blades of TCTs have to be considered to avoid the interruption of electricty generation during extrem weather. Val et al. [16] presented a probabilistic model to analyse the reliability of rotor baldes. The model considered the uncertainities associated with tidal current speed and the blade resistance. The model is able to calculate the bending moments in blades. Grogan et al.'s [15] results could be used in the blade design of TCTs. However, the proposed model is only applicable for pitchcontrolled devices.

The underwater conditions are more predictable and calm compared to the water surface in sea. Atmospheric hurricane does not exist underwater. Less action need to be taken to the tidal current power compared to the wind power technologies [2]. However, the surface wave generated by the extreme events may have negative influences on the performance of TCTs. Barltrop et al. [17] adopted linear wave theory into blade theory to investigate dynamic problems of TCTs. It shows that wave height has significant effect on the torque of rotor blades. The range of variation of torque on rotor blades is doubled when the wave height increases from 35 to $84 \mathrm{~mm}$. The torque further increases by $20 \%$ if $42 \mathrm{~mm}$ increment of wave height occurs. Galloway et al.'s [18] results agreed with Barltrop et al.'s [17] findings. Significant variation of thrust and torque was observed. These variations could influence the sustainability and fatigue of TCTs. Luznik et al. [19] demonstrated additional results of TCTs performance in an unsteady flow condition imposed by the surface wave. Luznik et al. [19] showed that the average power coefficient with waves is similar to the cases with the wave absence, but it has pronounced differences on the power production and blade loading. The extreme events could also bring flow debris in the marine environment. Most of manmade discarded objects are semisubmersible. The blade tips may be damaged by the debris.

The support structures of surface-piercing TCTs will be subjected to wave directly under extreme event. Wave studies on offshore wind turbines have been carried out extensively. The effect of extreme event on the tower base of TCTs can be referred to the established analogous knowledge from wind energy sector. Myrhaug and Holmedal [20] provide a practical method to estimated the wave run-up height on a slender circular cylindrical foundation for wind turbine. Zernov et al. [21] studied guided waves in a monopile for an offshore wind turbine. Marino et al. [22] draw some preliminary considerations about the direct wind effects on the kinetic and dynamic of steep extream waves propagating near offshore wind turbines. Marino et al. [23] presented a numerical model to simulate offshore wind turbine exposed to the extreme loading conditions. The mechanisms of kinetic energy to electricity conversion of these two technologies are similar [24]. The main difference between these two technologies is the fluid, where the density of seawater is approximately 832 times greater than the density of air [25]. But, the tower base of wind turbines and tidal turbines are subjected to seawater.

Generally, a 50-year return period wind speed has been assumed as the main design variable for the simulation of offshore wind turbines undergoing severe environmental conditions [23]. Such an extreme mean wind velocity induces sea states that is characterised as highly nonlinear irregular waves and this may break in proximity of the support structure giving rise to dangerous impact loads. International Standards such as IEC1400-3 [26] had recommended considerations for the extreme wave load.
Table 2

Main tower and substructure properties [33]

\begin{tabular}{ll}
\hline Main tower & \\
Tower base diameter, wall thickness & $6.00 \mathrm{~m}, 0.027 \mathrm{~m}$ \\
Tower top diameter, wall thickness & $3.87 \mathrm{~m}, 0.019 \mathrm{~m}$ \\
Main substructure & \\
Pile length, diameter & $20.00 \mathrm{~m}, 6.00 \mathrm{~m}$ \\
Pile wall thickness, total mass & $0.06 \mathrm{~m}, 190 \mathrm{t}$ \\
\hline
\end{tabular}

Marino et al. [23] in 2011 simulated offshore wind turbine under the exposure of extreme wave conditions. External condition-based extreme responses are reproduced by coupling a fully nonlinear wave kinematic solver with a hydro-aero-elastic simulator. This study was carried out based on "5-MW Reference Wind Turbine for Offshore System Development". All the technical characteristics of the model were documented by Jonkman et al. [27]. Relevant characteristics for the tower and substructure are demonstrated in Table 2. Jonkman et al. [27] simulated the overturning plunging breakers with high accuracy. The highest tower base bending moment can reach approximately $160 \mathrm{MN} \mathrm{m}$ (wave height $H_{s}=11.5 \mathrm{~m}$, wave period $T_{p}=10.6 \mathrm{~s}$ ). The impulsive force impact imposed to the substructure could be computed precisely when the kinematic of the plunging breakers is known [23].

Parambath [28] conducted a study to identify the impacts of tsunami on onshore wind power units. It concluded that surge/ bore more than $5 \mathrm{~m}$ brings failure to wind power unit tower. On the other hand, offshore wind turbine seems have survived in the Japan's tsunami in 2011 [29]. It concludes that support tower of TCTs may be able to survive under moderate extreme weather condition which does not induce significant wave height. However, the failure of TCTs is quite costly and some extreme events are not predictable. The potential sites of tidal farms with possibly low occurrence of extreme event has the priority for tidal energy development.

\section{Seabed scour}

At the planning stage of marine projects, the physical impacts imposed to the seabed by installing structures are required to study as part of environmental studies [40]. In this section, the local scour around the TCTs foundation is discussed. Scour around marine structures have been well recognised as an engineering issue where scour is likely to cause structural instability. Seabed protection for the foundation of marine structure is required [31-33]. As a marine structure, TCTs have the possibilities in experiencing seabed scour problems during its lifespan. Seabed scour issues have to be taken into account for a sound design of TCTs and their support structures.

Rambabu et al. [34] stated that the fluid flow, geometry of foundation and seabed conditions are the governing factors for the seabed scouring. The characteristics of fluid flow include the current velocity, Reynolds number and Froude number of flow. The above mentioned four types of foundations have different areas of contact to the seabed. The selection of support structures leads to different flow patterns occurring at the foundation with different formation of flow-induced vortices in the vicinity of support structures. Different scouring patterns are induced by different geometries of foundation.

The gravity structures of TCTs are most susceptible to seabed scouring due to its large contact area with the seabed compared to the other three types of foundation. The determination of geometry size and seabed preparation is required in order to implement the gravity structure as the foundation of TCT. The scour of monopile structures are less susceptible compared to gravity structures due to the low contact area with the seabed [6]. The 


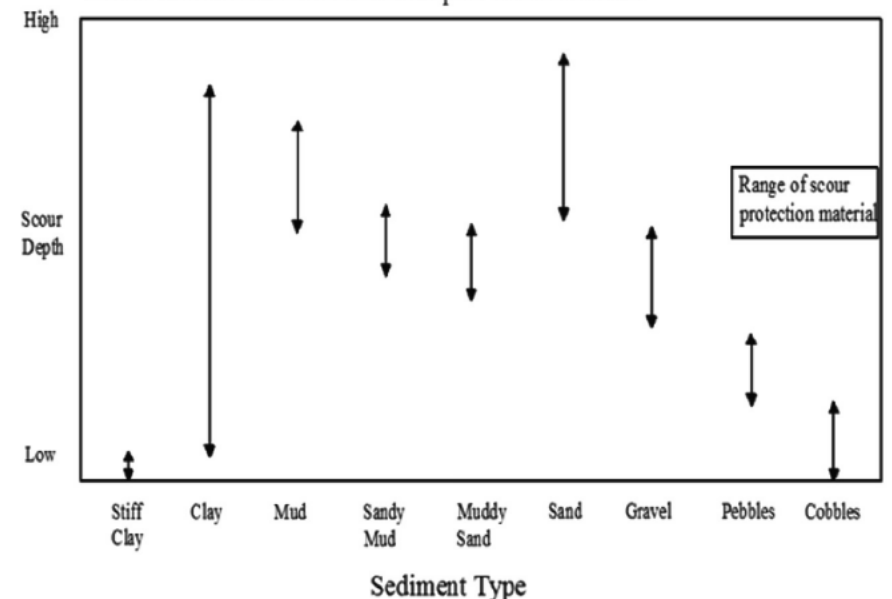

b
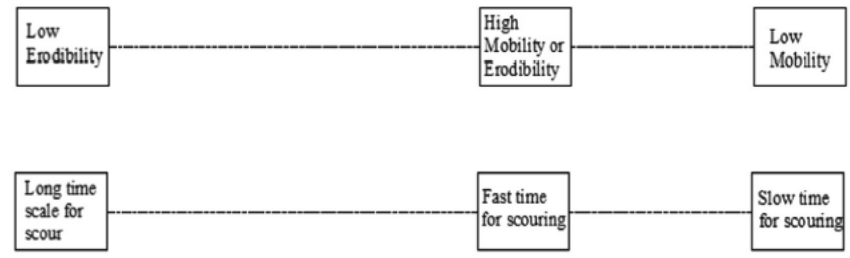

Tendency for scour to increase or decrease during extreme wave event(based on present knowledge)

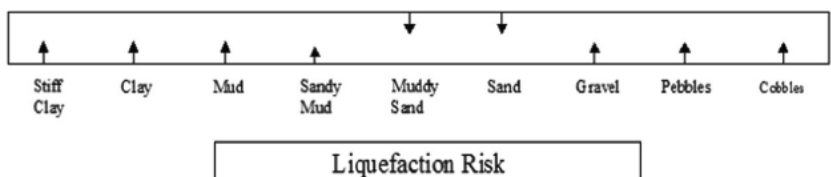

Fig. 1. Conceptual model for scour development around marine foundations.Modified from Whitehouse [38]

scour development around monopile structures has been studied extensively for the foundation of offshore wind turbine in the past few decades. The application of monopile structures in TCT is suggested for both the cost and structural stability [2]. The first tidal turbine in the world Seaflow is supported by a monopile, which succeeded in generating electricity [35]. The scour development of piled jacket structures is more complicated compared to the other support structures due to its footing shape [36] McDougal and Sulisz [37] stated that the floating structures give lowest impact on the seabed scour due to the low area of contact between the structure base and seabed. However, floating structure may have weaker mooring on the positioning of the turbine in harsh marine environment.

The seabed preparation is time consuming and the construction process of the foundation is costly. The potential sites for tidal current energy have normally fast flowing fluid, which may be dangerous for divers. Gravity structures may be suitable to the sites without the needs of excessive seabed preparation. Monopile structures can be used to replace the gravity structure as no seabed preparation is required prior to the installation [6]. The piled jacket and floating structures are both alternatives without seabed preparation. The floating structure needs solid points at seabed, fixing the structure to the seabed through chains.

Whitehouse [30] developed a conceptual model of scour sensitivity which includes full range of marine sediment types (Fig. 1a). The clay has the largest range of scour depth, where stiff clay has the lowest range of scour depth. The gravels, pebbles, and cobbles are suitable scour protection materials. According to Whitehouse [30], as the susceptibility of sediments to erosion reduces, the scour is expected to decrease for both coarser and finer soils in general terms, although muds and clays have more uncertainties regarding the response of scour due to their formation history and degree of compaction. Moreover, cyclic loading by waves may result in scouring due to pore pressure built up in the soil. Wave-induced liquefaction may occur and it could decrease the strength of soil. The information of soil subjected to liquefaction is illustrated in Fig. 1b [38]. The soils subject to liquefaction risk are clay, mud, sand mud, muddy sand and sand. Potential TCTs site with aforementioned soil condition need to be aware of liquefaction issue.

Meanwhile, further investigation of resistance to scour provided by clay in marine environment is needed and clay with 
undrained shear strength of order $100 \mathrm{kPa}$ is likely resistance to scouring under the condition of open sea environment. Jiang et al. [39] found a scour with $5 \mathrm{~m}$ depth in firm clay adjacent to an oilunloading terminal in a tidal river. Thus, stiff clay may also be treated as a scour hazard in some environments. Besides, marine soil consists of various layers and the understanding of multimodal sediment distribution is important for scour prediction [40]. Porter et al. [41] found that the seabed with the coarse sand overlaid by fine sand is more vulnerable to scour compared to the bed with uniform coarse sand.

In extreme events, the hydraulic force increases whilst the scouring depth of some sediment increases. On the contrary, some sediment waves may result in a decrease of scour depth. The scour depth of muddy sand and sand will decrease under extreme wave event. In addition, the events either with high energy for erosion occurrence or in long duration increase the rate of scour. Nevertheless, the scour response of the seabed in time-limited event depends on the sensitivity of the seabed to increased shearing force on seabed, and the severity of the event [30]. The extreme event not only impose direct load to the structure of TCTs (as discussed in Section 3.1), but also cause substantial erosion and scouring around the foundation of TCTs. The scour around the foundation of TCTs may result in instability of the support structure of TCTs.

To the best of authors' knowledge, no documented field measurement is available on the scour condition at real tidal farm sites. However, the filed measurements of scour condition in analogous wind turbine industry have been well documented. Whitehouse et al. [30] assessed the scour condition of several offshore wind turbine farms with monopile structures. The data of water depth, wave and current condition were collected for each site. The field measurement was made after 6 months of installation. The deepest scour was $1.47 D_{\text {pile }}$ (pile diameter $1.5 \mathrm{~m}$ ) in the current-dominated sandy environment according to Whitehouse et al. [30]. The offshore wind turbine was installed in a site with strong tidal current (peak current speed at $1.4 \mathrm{~m} / \mathrm{s}$ ) and also sheltered from waves. A wider range of offshore wind turbines have been assessed to further include the different scour conditions. The assessment concluded that scour of monopile at wind farm is a progressive process. The scour development depends on a range of tidal, seasonal and longer term variations in currents, wave action and the water depth at the foundation.

Additional factors need to be considered in the scour prediction of TCTs. TCTs has the special features of rotor, which may need to be taken into account. A seabed boundary layer is in the region between the seabed and rotor that will hit the foundation structure. The rotor causes the acceleration of the bed velocity between the rotor and seabed. The suppression of flow occurs to increase the stresses exerted on the seabed and consequently leads to the seabed scouring. Chen and Lam [42] claimed that the clearance between rotor and seabed becomes critical in the TCTs induced scour

Table 3

2 MW turbine specification.

\begin{tabular}{ll}
\hline Rated power $(\mathrm{MW})$ & 2.0 \\
Rotor diameter $(\mathrm{m})$ & 22.8 \\
Blade length $(\mathrm{m})$ & 10.5 \\
Number of blades & 3 \\
Rated hub flow speed $(\mathrm{m} / \mathrm{s})$ & 3.0 \\
Rated rotor speed $(\mathrm{rpm})$ & 12.0 \\
Hub height above seabed & 29.0 \\
Control type & Pitch regulated, variable speed \\
Transmission & Gear-box \\
Support structure & Bottom-mounted tripod \\
Foundation stiffness & Rigid \\
\hline
\end{tabular}

prediction. The closest equations can be used to predict the scour of TCTs monopile discussed by Chen and Lam [42].

\subsection{Fatigue failure}

The blades of TCTs are generally designed for 25-year lifespan and the blades are expected to withstand all potential loads during the lifespan. The static load imposed on TCTs is higher than wind turbine due to the high density of seawater. On the other hand, the randomness of ocean current integrated with turbulence and velocity shear generate fatigue load on the TCTs' blade. Furthermore, the TCTs' blades are submerged in corrosive marine environment. Thus, investigations of TCTs under static and fatigue load are necessary. Survivability of TCTs under fatigue load could help in sound design to ensure safe operational life cycle and successful energy extraction [43]. Composites materials have been adopted in the prototype turbines for better fatigue behaviour. A $65 \mathrm{~mm}$ thick carbon fibrereinforced spar bonded to fibreglass ribs and sheathed with a fibreglass-reinforced skin was featured in the rotor of Seaflow (2003). The rotor uses a marine-quality epoxy resin matrix. The spar was made of proprietary prepreg, and it vacuum-bagged and cured in an oven at a temperature of $75{ }^{\circ} \mathrm{C}$ [44]. The blades of commercial tidal project SeaGen (2008) consist of a hollow carbon fibre composite box spar. The spar acts as the main load bearing member [45].

Fatigue failure is potentially caused by the load that varies with time. The load tends to vary in amplitude and frequency over time. McCann et al. [46] carried out analysis on the fatigue loading sensitivity of TCTs to waves and turbulence. McCann et al. [46] assessed the loading sensitivity to variations in flow turbulence intensity (TI) and wave actions (characterised by wave height $H_{s}$ and period $T_{p}$ ). McCann et al. [46] chose blade root out-of-plane bending moment $\left(M_{y}\right)$ in order to investigate the critical fatigue load.

The fatigue load simulations were modelled based on the Germanischer Lloyd guidelines for ocean energy converters [47]. A 2 MW tidal turbine has been used for the simulation. The detailed description of the turbine model is indicated in Table 3. The critical fatigue load has been identified throughout the simulation. The material properties, safety factor adopted and actual load level involved in the TCTs are the variables of critical fatigue load and extreme loading. To offer a benchmark for assessing the critical fatigue load, simulation of a single extreme load case was conducted based on 50-year extreme wave event at peak current, as shown in Table 4. In this extreme load case, maximum blade root bending moment $\left(M_{x y}\right)$ is extracted. From the simulation results, maximum blade root out-of-plane bending moment $\left(M_{y}\right)$ has been extracted with a value of $4429 \mathrm{kN}$ m before the adoption of safety factor. To analyse the extreme yield as well as comparing the extreme and fatigue loads, blade root component has been modelled through simulating a simple cylindrical section of constant wall thickness. The material used to manufacture the root is assumed to be CFRP. The properties of CFRP are demonstrated in Table 5.

According to fatigue load, blade root geometry and materials properties, the fatigue stress reserve margins has been calculated by McCann et al. [46]. It has been observed that the stress margin fall to as low as $8 \%$ under certain environment, as shown in Tables 6 and 7. A positive margin indicated that fatigue failure is not predicted to

\begin{tabular}{|c|c|}
\hline Peak flow speed $(\mathrm{m} / \mathrm{s})$ & 3.5 \\
\hline Mean flow turbulence intensity (\%) & 10 \\
\hline Extreme stream $f_{n}$ wave $H, T(\mathrm{~m}, \mathrm{~s})$ & 10,15 \\
\hline Wave, current direction & In line \\
\hline
\end{tabular}

Link to Full-Text Articles :

http://www.sciencedirect.com/science/article/pii/S1364032114010107 